DOI 10. 18307/2018. 0523

(C) 2018 by Journal of Lake Sciences

\title{
富营养化湖泊夏季表层水体温室气体浓度及其影响因素"
}

间兴成 ${ }^{1,2}$, 张重乾 ${ }^{1,2}$, 季 铭 ${ }^{1,2}$, 王明玥 ${ }^{1,2}$, 再珊珊 ${ }^{1,2}$, 许晓光 ${ }^{1,2}$, 王国祥 ${ }^{1,2 * *}$

( 1 : 南京师范大学环境学院, 南京 210023)

( 2 : 江苏省地理信息资源开发与利用协同创新中心, 江苏省环境演变与生态建设重点实验室, 江苏省水土环境生态修复

工程实验室, 南京 210023)

摘 要: 为研究富营养化湖泊水体温室气体浓度及其影响因素, 以太湖西岸和竺山湾为例, 共调查研究了 27 个点位, 采 用顶空平衡法对其表层水体中溶解的甲烷 $\left(\mathrm{CH}_{4}\right)$ 和氧化亚氮 $\left(\mathrm{N}_{2} \mathrm{O}\right)$ 浓度进行测定. 结果表明, 太湖近岸带蓝藻水华堆积 区表层水体中 $\mathrm{CH}_{4}$ 和 $\mathrm{N}_{2} \mathrm{O}$ 两种温室气体浓度远远高于开阔湖区点位, $\mathrm{CH}_{4}$ 和 $\mathrm{N}_{2} \mathrm{O}$ 最高浓度分别为 $3.79 \pm 0.095$ 和 $0.078 \pm$ $0.003 \mu \mathrm{mol} / \mathrm{L}$. 蓝藻水华堆积区和开阔湖区 $\mathrm{CH}_{4}$ 平均浓度分别为 $2.33 \pm 1.46$ 和 $0.14 \pm 0.059 \mu \mathrm{mol} / \mathrm{L}, \mathrm{N}_{2} \mathrm{O}$ 的平均浓度分别 为 $0.054 \pm 0.024$ 和 $0.023 \pm 0.012 \mu \mathrm{mol} / \mathrm{L}$. 两种气体在水中均呈现过饱和状态, 其中蓝藻水华堆积区表层水体中 $\mathrm{CH}_{4}$ 和 $\mathrm{N}_{2} \mathrm{O}$ 饱和度远远高于开阔湖区点位. 此外, 人湖河流河口区域表层水体溶解性 $\mathrm{N}_{2} \mathrm{O}$ 浓度较高. 将水中 $\mathrm{CH}_{4}$ 和 $\mathrm{N}_{2} \mathrm{O}$ 浓度与水体 环境因子之间进行相关性分析, 表明水体总氮、总磷、铵态氮和溶解性有机碳浓度与 $\mathrm{CH}_{4}$ 和 $\mathrm{N}_{2} \mathrm{O}$ 浓度呈显著正相关, $\mathrm{CH}_{4}$ 浓度与硝态氮浓度呈显著负相关. 研究结果揭示了太湖蓝藻水华堆积区是 $\mathrm{CH}_{4}$ 和 $\mathrm{N}_{2} \mathrm{O}$ 两种温室气体重要的潜在排放源, 蓝藻水华暴发对湖泊温室气体的排放具有重要影响, 但该过程的驱动机制及影响因素仍需要进一步研究.

关键词: 太湖;蓝藻暴发;表层水体;温室气体; 影响因素

\section{Concentration of dissolved greenhouse gas and its influence factors in the summer surface water of eutrophic lake}

YAN Xingcheng ${ }^{1,2}$, ZHANG Zhongqian ${ }^{1,2}$, JI Ming ${ }^{1,2}$, WANG Mingyue $^{1,2}$, RAN Shanshan ${ }^{1,2}$, XU Xiaoguang $^{1,2} \&$ WANG Guoxiang ${ }^{1,2 * *}$

(1: School of Environment, Nanjing Normal University, Nanjing 210023, P.R. China)

(2: Jiangsu Center for Collaborative Innovation in Geographical Information Resource Development and Application, Jiangsu Key Laboratory of Environmental Change and Ecological Construction, Jiangsu Engineering Laboratory of Water and Soil Eco-remediation, Nanjing 210023, P.R.China)

Abstract: In order to study the concentration of dissolved greenhouse gas and its influence factors in the surface water of eutrophic lake, the west shore and Zhushan Bay of Lake Taihu were taken as an example. The concentrations of dissolved $\mathrm{CH}_{4}$ and $\mathrm{N}_{2} \mathrm{O}$ in the surface water of 27 sites were determined by using headspace equilibrium method. Results indicated that concentrations of dissolved $\mathrm{CH}_{4}$ and $\mathrm{N}_{2} \mathrm{O}$ in the cyanobacteria blooms accumulated zone were much higher than those from the open lake area, with the highest value of $3.79 \pm 0.095$ and $0.078 \pm 0.003 \mu \mathrm{mol} / \mathrm{L}$, respectively. The average concentrations of dissolved $\mathrm{CH}_{4}$ in the cyanobacteria blooms accumulated zone and open lake area were $2.33 \pm 1.46$ and $0.14 \pm 0.059 \mu \mathrm{mol} / \mathrm{L}$, and $\mathrm{N}_{2} \mathrm{O}$ concentration were $0.054 \pm$ 0.024 and $0.023 \pm 0.012 \mu \mathrm{mol} / \mathrm{L}$, respectively. The two greenhouse gases were all over saturated in the study sites, and the saturability of the greenhouse gases in the cyanobacteria blooms accumulated zone was much higher than that from the open lake. Additionally, concentrations of $\mathrm{N}_{2} \mathrm{O}$ in the estuaries of inflow rivers were higher than other sites. The results of correlation analysis indicated that the concentrations of dissolved $\mathrm{CH}_{4}$ and $\mathrm{N}_{2} \mathrm{O}$ were significantly and positively correlated with total nitrogen, total phos-

* 国家水体污染控制与治理科技重大专项(2017ZX07203-003)、江苏省太湖水环境综合治理科研项目 ( JSZC-G2014212)、国家自然科学基金项目(41573061)、江苏省太湖水环境综合治理科研项目 (TH2015202)、国家自然科学基 金项目 (41573105) 和江苏省高等学校自然科学研究面上项目 (17KJB170009) 联合资助. 2018-01-16 收稿; 201803-03 收修改稿. 间兴成 (1993 ), 男,硕士研究生;E-mail: 15651658250@ 163.com.

** 通信作者;E-mail:wangguoxiang@ njnu.edu.cn. 
phorus, ammonium nitrogen and dissolved organic carbon, while the concentrations of the dissolved $\mathrm{CH}_{4}$ was significantly and negatively correlated with nitrate nitrogen. This study indicated that the littoral zone, especially the cyanobacteria blooms accumulated zone plays a potential role in greenhouse gas emission from water to the atmosphere. Moreover, the occurrence of cyanobacteria blooms may facilitated the production of $\mathrm{CH}_{4}$ and $\mathrm{N}_{2} \mathrm{O}$, but the driving mechanism and influence factors during this process need further investigations.

Keywords: Lake Taihu; cyanobacteria blooms; surface water; greenhouse gas; influence factors

内陆淡水生态系统在全球温室气体排放量中具有重要贡献, 全球淡水生态系统甲烷 $\left(\mathrm{CH}_{4}\right)$ 排放量折算 为二氧化碳 $\left(\mathrm{CO}_{2}\right)$ 量甚至能够抵消陆地生态系统碳吸收量的 $25 \%^{[1-2]}$. 湖泊作为内陆水圈的重要组成部 分 ${ }^{[3]}$, 流域尺度上由自然或者人为活动向湖泊输人的营养负荷都会导致湖泊生态系统碳、氮等的积累 ${ }^{[4]}$. 对 于湖泊生态系统来说, 任何加速有机质转化的因子都会对湖泊生物地球化学循环产生重要影响, 同时也会 促进温室气体在湖泊水一气界面的交换 ${ }^{[5]} . \mathrm{CH}_{4}$ 和氧化亚氮 $\left(\mathrm{N}_{2} \mathrm{O}\right)$ 作为大气中重要的温室气体, 在湖泊沉积 物和水体中均存在产生和消耗的过程 ${ }^{[5]}$. 尽管湖泊面积占地球陆地表面积仅为 $3.7 \%{ }^{[6]}$, 但其在全球碳循环 以及气候调控中具有不可忽略的重要作用 ${ }^{[2,7-8]}$. 因此, 湖泊温室气体的产生和消耗过程对大气中温室气体 的浓度以及热量收支具有重要意义 ${ }^{[7]}$. 近年来, 关于富营养化湖泊温室气体的产生、排放等问题也逐渐成为 研究热点.

关于湖泊温室气体排放通量的相关问题国外研究者开展得较早, 并取得了一系列的研究成果. Bastviken 等 ${ }^{[9]}$ 通过对全球湖泊 $\mathrm{CH}_{4}$ 排放量进行估算, 结果表明, 湖泊 $\mathrm{CH}_{4}$ 排放量相对 $\mathrm{CO}_{2}$ 来说较小, 为 $8 \sim 48$ $\mathrm{Tg} \mathrm{C} / \mathrm{a}$, 同时在对全球 $\mathrm{CH}_{4}$ 排放量的估算过程中应当把湖泊这一重要排放源考虑进去. Huttunen 等 ${ }^{[10]}$ 对芬 兰一些湖泊 $\mathrm{CH}_{4}$ 的排放进行研究, 结果表明, 湖泊的营养状态、冬季水体的含氧量以及冰面覆盖对来年春季 $\mathrm{CH}_{4}$ 的排放具有重要影响, 冬季冰面覆盖时期产生的 $\mathrm{CH}_{4}$ 在冰融化时会向大气释放 ( $3.6 \sim 7.9 \mathrm{~g} \mathrm{CH}_{4} / \mathrm{m}^{2}$ ). 此 外, 在温室气体排放途径 ${ }^{[9]}$ 、影响因素 ${ }^{[1-13]}$ 等方面也取得了相关成果. 国内学者 Wang 等 ${ }^{[14-15]}$ 对太湖梅梁湾 $\mathrm{CH}_{4}$ 和 $\mathrm{N}_{2} \mathrm{O}$ 排放通量的研究表明, $\mathrm{CH}_{4}$ 排放量最高达到 $131 \mathrm{mg} \mathrm{CH}_{4} /\left(\mathrm{m}^{2} \cdot \mathrm{h}\right)$, 湖泊近岸带 $\mathrm{N}_{2} \mathrm{O}$ 排放量最高, 达到 $2101 \mu \mathrm{g} \mathrm{N} \mathrm{N}_{2} \mathrm{O} /\left(\mathrm{m}^{2} \cdot \mathrm{h}\right)$. Xing 等 ${ }^{[16]}$ 对武汉东湖 $\mathrm{CH}_{4}$ 排放通量的研究表明, $\mathrm{CH}_{4}$ 平均排放通量为 $332.3 \pm$ $160.1 \mathrm{mg} /\left(\mathrm{m}^{2} \cdot \mathrm{d}\right)$, 其排放通量在夏季达到最高.

现有的大多数研究采用静态箱法对湖泊近岸带温室气体排放通量进行观测, 而对于开阔湖区, 由于风 浪扰动较大, 静态箱法不便于操作. 除静态箱观测法外, 顶空平衡法也是较为常用的方法之一, 虽然其不能 像静态箱法一样直接反映温室气体从水体向大气排放的量, 但是按照基本理论, 水中温室气体向大气发生 交换的前提条件是气体在两相之间存在浓度梯度. 除浓度梯度外, 水中温室气体向大气的交换速率受气体 扩散系数的影响, 该扩散系数与水体扰动密切相关, 如风速 ${ }^{[9]}$ 等. 因此, 气体在表层水体的溶存浓度及饱和 度在一定程度上能够反映出气体向大气迁移的潜力. 本研究选择我国典型富营养化浅水湖泊太湖作为研究 对象, 采用顶空平衡法对竺山湾和太湖西岸近岸带表层水体 $\mathrm{CH}_{4}$ 和 $\mathrm{N}_{2} \mathrm{O}$ 两种温室气体的浓度进行测定, 同 时计算了两种温室气体在水中的饱和度, 分析其与水质指标之间的关系, 为今后太湖温室气体排放的深人 研究提供参考.

\section{1 材料与方法}

\section{1 采样点位}

于 2017 年 8 月在太湖竺山湾和西岸近岸带共采集 27 个样品,其中点位 1 和 2 均位于西岸芦苇带的槽 沟内,蓝藻水华在外力作用下常在此聚集堆积. 相比于其他点位, 点位 1 和 2 的蓝藻水华聚集严重, 其中样 点 2 最为严重. 点位 3 27 均为开阔湖区, 无明显蓝藻堆积 (图 1). 虽然太湖蓝藻水华在 4-5 月份已经形 成,如果开展整个蓝藻水华从形成一暴发一衰亡整个过程中的研究更具有代表性,但是本研究所选择的区 域为富营养化较为严重的竺山湾和太湖西岸, 采样时间为 8 月份, 此时调查区域蓝藻水华仍然较为严重,温 度较高, 研究范围较广, 采样点位较多, 而且近岸带和开阔湖区区域本身蓝藻生物量具有一定差异, 增强了 研究结果的可靠性. 

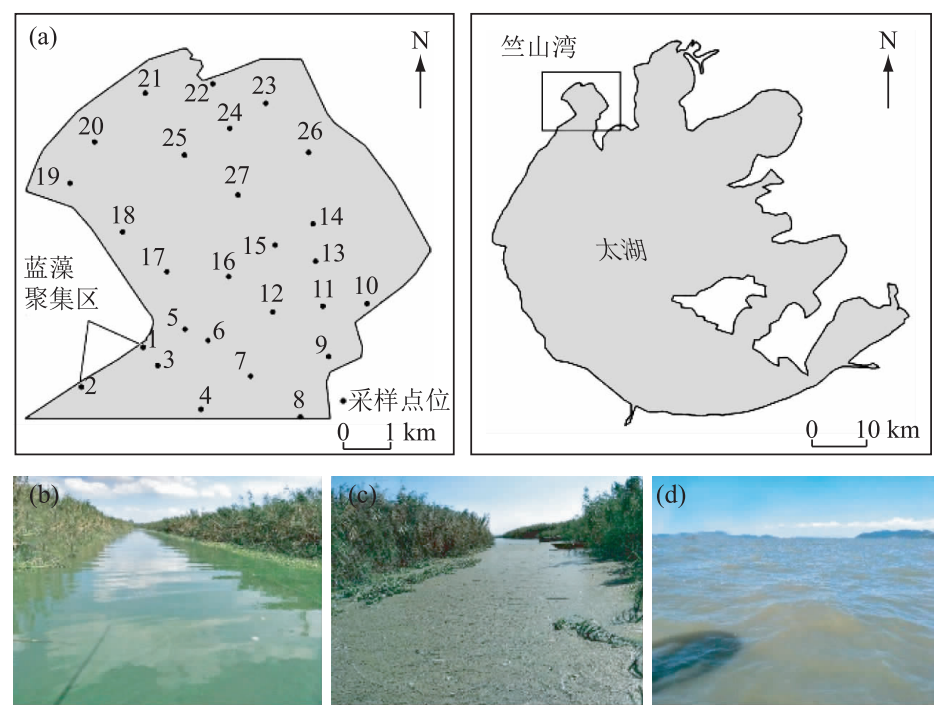

图 1 采样点位示意图 (a) 以及现场图 (b:点位 1 ; $c$ : 点位 2 ; $d$ : 点位 3 27)

Fig.1 Sampling sites (a) and field pictures of sampling sites 1 (b),2 (c) and 3-27 (d)

\section{2 采样与分析方法}

到达点位后, 尽量避免对水体造成过多的扰动, 用针筒注射器缓慢吸取表层 $0 \sim 10 \mathrm{~cm}$ 的水样, 注人 23 $\mathrm{ml}$ 预先加人 $0.05 \mathrm{ml} \mathrm{HgCl}$ 的血清瓶中, 迅速用塞子和盖子密封, 避光低温保存, 待测两种温室气体, 每个点 做 3 个平行, 并用 $1 \mathrm{~L}$ 水样瓶采集表层水样用于测定营养盐浓度. 水体温度、 $\mathrm{pH}$ 、溶解氧 ( DO ) 、氧化还原电 位 $(\mathrm{ORP})$ 、电导率 $(\mathrm{EC})$ 用便携式水质分析仪测定 (YSL, USA).

水中溶解的温室气体浓度采样顶空平衡法测定. 用 $5 \mathrm{ml}$ 超纯氮气 (纯度 $99.9999 \%$ ) 置换血清瓶中的水 样后, $25^{\circ} \mathrm{C}$ 水浴加热, 剧烈摇晃 $2 \mathrm{~min}$ 后, 用注射器抽取 $2 \mathrm{ml}$ 顶空气体注人气相色谱仪 (Agilent 7890B, USA) 中测定 $\mathrm{CH}_{4}$ 和 $\mathrm{N}_{2} \mathrm{O}$ 含量. 水样测定总氮 $(\mathrm{TN})$ 、总磷 $(\mathrm{TP})$ 、铵态氮 $\left(\mathrm{NH}_{4}^{+}-\mathrm{N}\right)$ 、硝态氮 $\left(\mathrm{NO}_{3}^{-}-\mathrm{N}\right)$ 、溶解性有机碳 (DOC) 和磷酸盐 $\left(\mathrm{PO}_{4}^{3-}-\mathrm{P}\right)$ 浓度等指标. $\mathrm{TN} 、 \mathrm{TP}$ 浓度采用碱性过硫酸钾联合消解法测定; $\mathrm{NH}_{4}^{+}-\mathrm{N} 、 \mathrm{NO}_{3}^{-}-\mathrm{N}$ 和 $\mathrm{PO}_{4}^{3-}-\mathrm{P}$ 浓度用连续流动分析仪 (Auto Analyzer 3, 德国) 测定, DOC 浓度用 TOC 分析仪 (岛津 TOC-L, 日本) 测定.

数据作图及分析分别采用 Origin 8.5 和 SPSS 18.0 软件.

\section{3 水体温室气体浓度及饱和度的计算}

水中温室气体的饱和度计算公式为:

$$
R=C_{1} / C_{\text {eq }} \times 100
$$

式中, $R$ 为温室气体在水中的饱和度 $(\%), C_{1}$ 为气体在水中的浓度, $C_{\mathrm{eq}}$ 为与大气达到平衡时水中温室气体的 理论平衡浓度,利用两种气体在大气中的平均浓度及测得的水体温度, 参照 Weiss 等 ${ }^{[17]}$ 和 Wiesenburg 等 ${ }^{[18]}$ 的公式进行计算, 其中 $\mathrm{CH}_{4}$ 和 $\mathrm{N}_{2} \mathrm{O}$ 在大气中的平均体积浓度为 $1.8 \times 10^{-6}$ 和 $324.7 \times 10^{-9}$ (数据来源为中国气象 局官网, 两种气体的平均值为 2011 年瓦里关大气本底站观测值).

水中温室气体的浓度等于气相浓度与平衡时液相气体浓度之和, 顶空内气体浓度由 Dalton 分压定律计 算, 平衡时水中 $\mathrm{N}_{2} \mathrm{O}$ 浓度参照文献 [17]计算, $\mathrm{CH}_{4}$ 浓度参照文献 [ 18]计算,具体的计算方式见文献 [19].

\section{2 结果与分析}

\section{1 表层水体温室气体浓度}

各点位表层水体溶解的温室气体浓度总体上表现为西岸蓝藻聚集区远远高于其他点位. 其中点位 2 最 高, $\mathrm{CH}_{4}$ 和 $\mathrm{N}_{2} \mathrm{O}$ 浓度分别为 $3.79 \pm 0.095 \mu \mathrm{mol} / \mathrm{L}$ 和 $0.078 \pm 0.003 \mu \mathrm{mol} / \mathrm{L}$. 湖面开阔区点位表层水体 $\mathrm{CH}_{4}$ 和 
$\mathrm{N}_{2} \mathrm{O}$ 浓度分别为 $0.019 \sim 0.24 \mu \mathrm{mol} / \mathrm{L}$ 和 $0.011 \sim 0.53 \mu \mathrm{mol} / \mathrm{L}$. 蓝藻水华堆积区和开阔湖区 $\mathrm{CH}_{4}$ 平均浓度分别 为 $2.33 \pm 1.46 \mu \mathrm{mol} / \mathrm{L}$ 和 $0.14 \pm 0.059 \mu \mathrm{mol} / \mathrm{L}, \mathrm{N}_{2} \mathrm{O}$ 的平均浓度分别为 $0.054 \pm 0.024 \mu \mathrm{mol} / \mathrm{L}$ 和 $0.023 \pm 0.012$ $\mu \mathrm{mol} / \mathrm{L}$. 同时也不难看出, 除了蓝藻聚集区域外, 太湖竺山湾北部点位 (点位 $21 \sim 24$ ) 和西部点位 19 表层水 体的 $\mathrm{N}_{2} \mathrm{O}$ 浓度也较高(图 2).

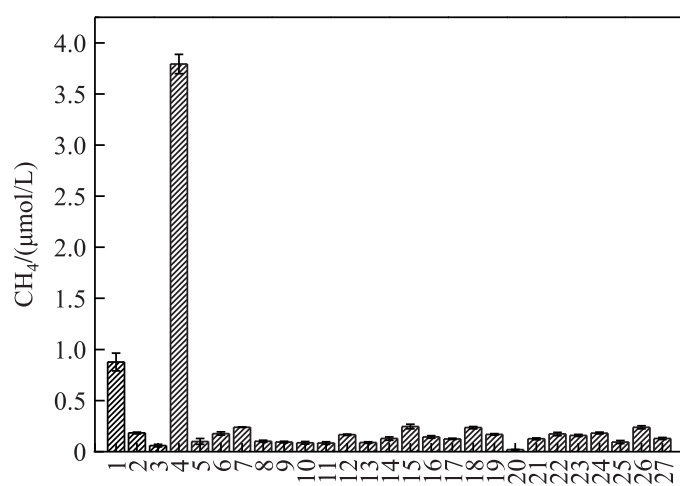

采样点位

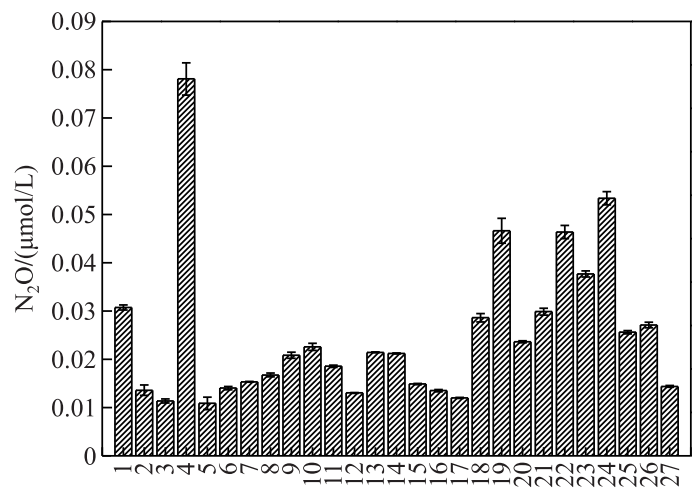

采样点位

图 2 表层水体温室气体浓度

Fig. 2 Concentrations of dissolved greenhouse gases in the surface water

\section{2 两种温室气体在水中的饱和度}

各点位两种温室气体在水中均呈为过饱和, 表明这两种温室气体均具有向大气迁移的潜力. 两种气体 在水中的饱和度与其在水体中浓度的空间差异一致. 其中点位 2 水体的 $\mathrm{CH}_{4}$ 和 $\mathrm{N}_{2} \mathrm{O}$ 饱和度最高, 分别为 $175797 \%$ 和 $1220 \%, \mathrm{CH}_{4}$ 的饱和度是 $\mathrm{N}_{2} \mathrm{O}$ 的 144 倍. 西岸近岸点点位 1 的 $\mathrm{CH}_{4}$ 饱和度也较高, 达到 40694\% 和 $650 \%$. 此外, 竺山湾北部水体 $\mathrm{N}_{2} \mathrm{O}$ 饱和度较高. 总体来看, 近岸带蓝藻水华聚集区两种温室气体的排放潜力 较其他点位大, 竺山湾北部也可能是 $\mathrm{N}_{2} \mathrm{O}$ 较为重要的排放区域( 图 3 ).

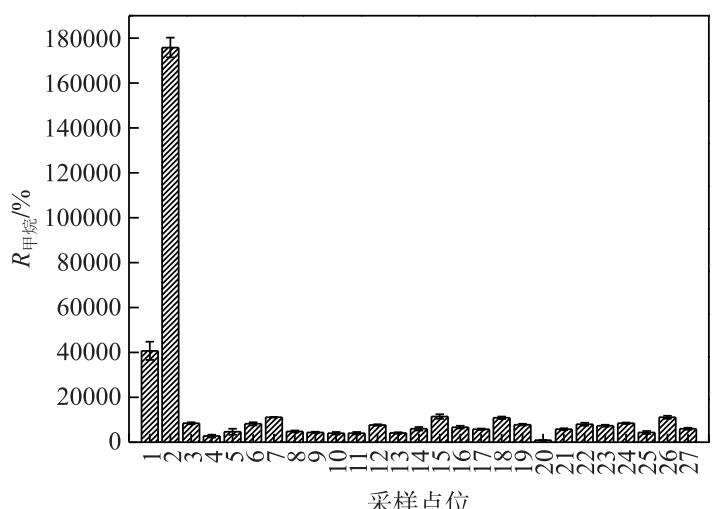

采样点位

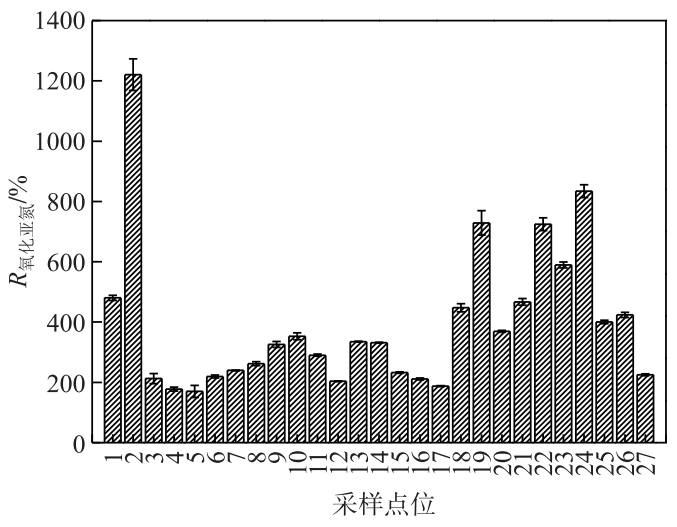

采样点位

图 3 表层水体温室气体的饱和度

Fig.3 Saturations of dissolved greenhouse gases in the surface water

\section{3 水体营养盐浓度特征}

总体来看,西岸近岸点位 1 和 2 的营养盐浓度较高. 其中 $\mathrm{TN} 、 \mathrm{TP} 、 \mathrm{NH}_{4}^{+}-\mathrm{N}$ 和 DOC 浓度于点位 2 (蓝藻水

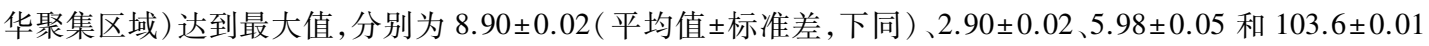
$\mathrm{mg} / \mathrm{L}$, 而 $\mathrm{NO}_{3}^{-}-\mathrm{N}$ 浓度在点位 2 最低, 为 $0.006 \pm 0.004 \mathrm{mg} / \mathrm{L}$. 此外, 点位 3 由于采样时水面有蓝藻, 因此其 $\mathrm{TN}$ 和 TP 浓度也较高, 分别达到 $6.65 \pm 0.17$ 和 $1.01 \pm 0.06 \mathrm{mg} / \mathrm{L}$. 点位 $5 \sim 27$ 的 $\mathrm{NH}_{4}^{+}-\mathrm{N}$ 浓度较低, 为 $0.041 \sim 0.17$ 
$\mathrm{mg} / \mathrm{L}$. 蓝藻聚集区 (点位 1 和 2) $\mathrm{NO}_{3}^{-}-\mathrm{N}$ 浓度低于开阔湖区, 点位 $3 \sim 27$ 的 $\mathrm{NO}_{3}^{-}-\mathrm{N}$ 浓度为 $0.63 \sim 2.39 \mathrm{mg} / \mathrm{L}$. 总 体上看, 竺山湾西部点位 19 、北部点位 (点位 $21 \sim 26$ ) 以及东部 (点位 $13 \sim 15$ ) $\mathrm{NO}_{3}^{-}-\mathrm{N}$ 浓度较高. 而各点的 $\mathrm{PO}_{4}^{3-}-\mathrm{P}$ 浓度无明显变化规律, 其平均浓度为 $0.029 \sim 0.1 \mathrm{mg} / \mathrm{L}$. DOC 浓度在除点位 2 外的其他点位均较低, 平 均值为 $12.15 \sim 28.9 \mathrm{mg} / \mathrm{L}$ ( 图 4).
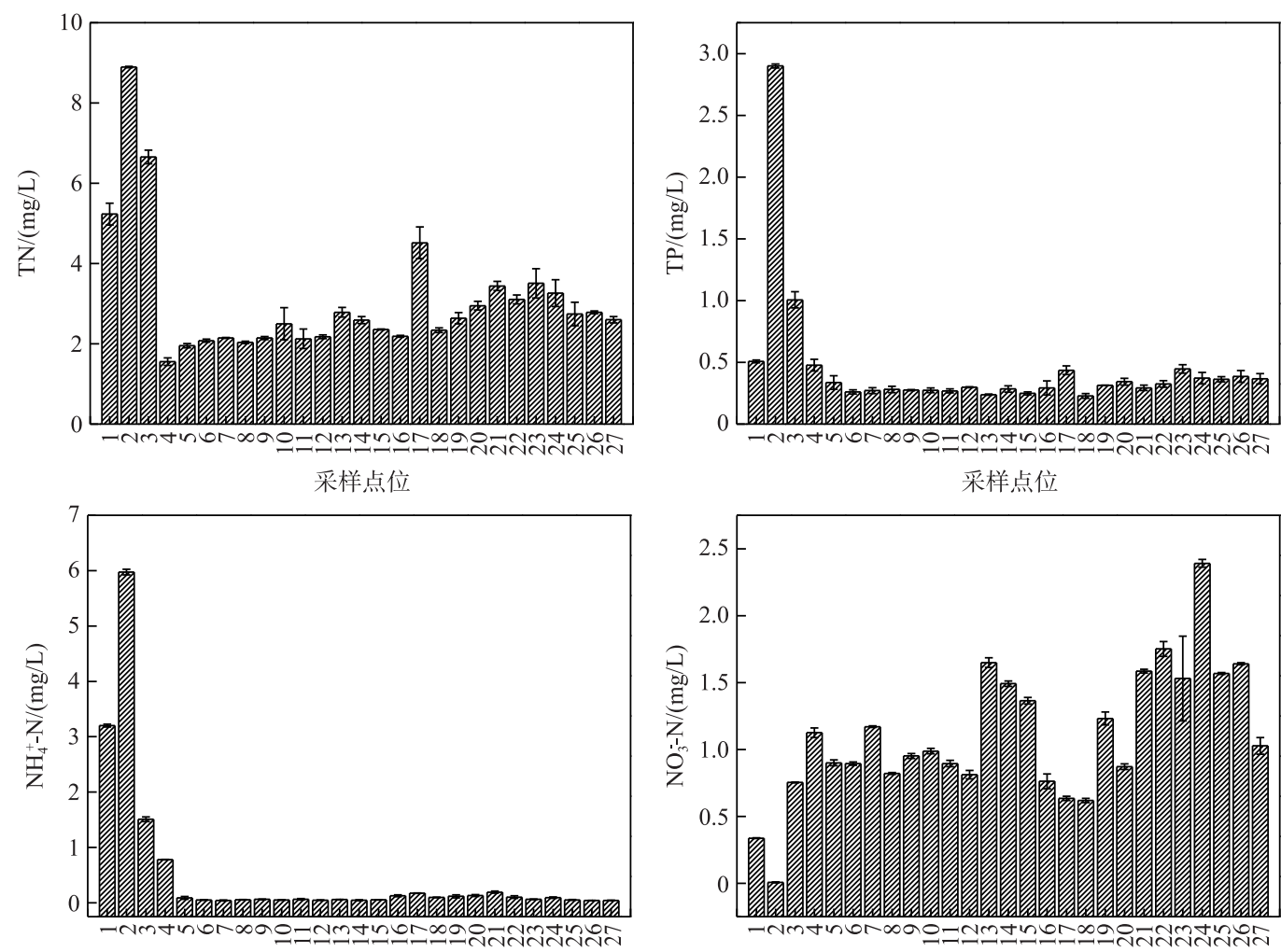

采样点位
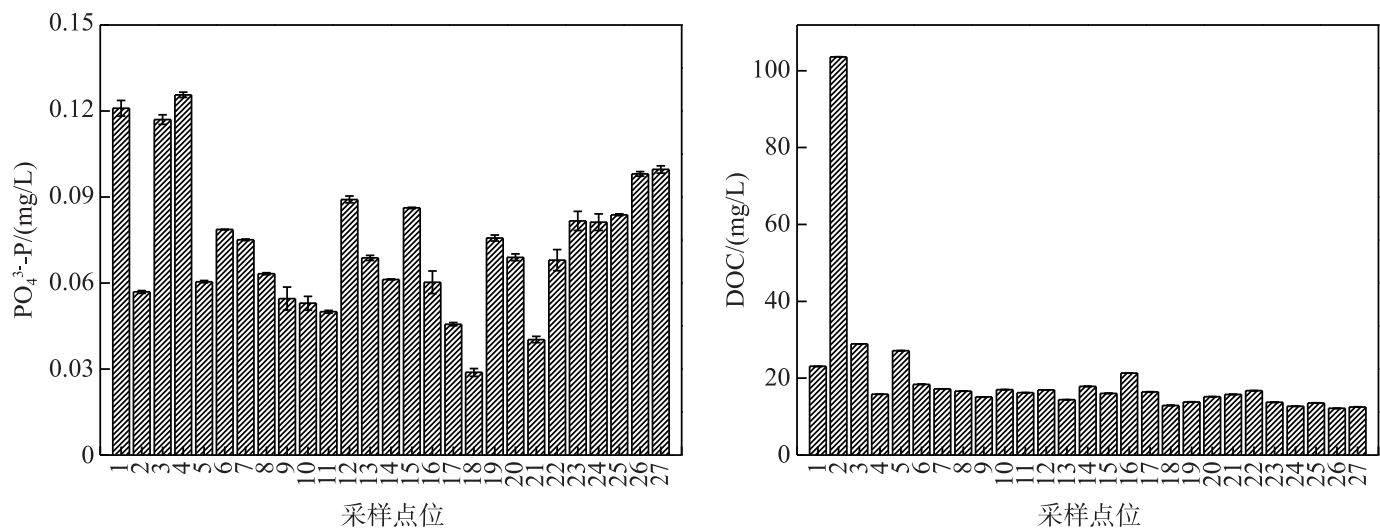

图 4 表层水体营养盐浓度

Fig.4 Concentrations of nutrients in the surface water

\section{4 水体中两种温室气体溶存浓度与水体理化指标之间的关系}

水体中 $\mathrm{CH}_{4}$ 和 $\mathrm{N}_{2} \mathrm{O}$ 浓度与 $\mathrm{TN} 、 \mathrm{TP} 、 \mathrm{NH}_{4}^{+}-\mathrm{N}$ 和 DOC 浓度的相关性显著 $(P<0.01$, 表 1$) . \mathrm{CH}_{4}$ 浓度与 DOC 浓度相关性最为显著, 表明水中的 DOC 在微生物的代谢作用下可能会对 $\mathrm{CH}_{4}$ 的产生具有重要影响. 
表 1 表层水体温室气体浓度与水体环境因子之间的相关性分析

Tab.1 Correlations between dissolved greenhouse gas contents and environmental factors in the surface water

\begin{tabular}{ccccccccccc}
\hline & $\mathrm{pH}$ & $\mathrm{DO}$ & $\mathrm{ORP}$ & $\mathrm{EC}$ & $\mathrm{TN}$ & $\mathrm{TP}$ & $\mathrm{NO}_{3}^{-}-\mathrm{N}$ & $\mathrm{NH}_{4}^{+}-\mathrm{N}$ & $\mathrm{DOC}$ & $\mathrm{PO}_{4}^{3-}-\mathrm{P}$ \\
\hline $\mathrm{CH}_{4}$ & -0.178 & -0.083 & -0.094 & 0.017 & $0.780^{* *}$ & $0.944^{* *}$ & $-0.491^{*}$ & $0.926^{* *}$ & $0.961^{* *}$ & -0.070 \\
$\mathrm{~N}_{2} \mathrm{O}$ & -0.210 & -0.182 & 0.068 & $0.552^{* *}$ & $0.557^{* *}$ & $0.629^{* *}$ & $0.111^{* *}$ & $0.582^{* *}$ & $0.582^{* *}$ & -0.121 \\
\hline
\end{tabular}

* 表示在 $P<0.05$ 水平上相关性显著; $* *$ 表示在 $P<0.01$ 水平上相关性显著, $n=27$.

\section{3 讨论}

本研究中, 湖泊近岸带点位两种温室气体浓度及饱和度高于开阔湖区点位, 表明湖泊近岸带在其温室 气体排放过程中发挥着重要的作用,具有非常大的排放潜力. 湖泊近岸带是蓝藻水华聚集的主要场所,太湖 西岸芦苇群丛蓝藻聚集严重, 湖泊中产生的蓝藻水华在风力等外力的作用下常在此聚集、分解, 其分解过程 会导致周边水体理化环境产生显著改变, 如低溶解氧、强烈的还原环境 ${ }^{[14]}$, 同时会释放大量的营养盐以及有 机质 ${ }^{[20]}$. 蓝藻从上覆水体沉降至表层沉积物的过程中, 会被水和沉积物中的细菌利用, 大大增加发酵型微 生物丰度 ${ }^{[21]}$, 同时促进水体和沉积物异养微生物的生长 ${ }^{[22]}$.

$\mathrm{CH}_{4}$ 是有机质在厌氧条件下矿化的最终产物 ${ }^{[23]}$, 其产生过程需要利用 3 种类型微生物 (水解细菌、产氢 产乙酸细菌以及产甲烷细菌 $)^{[24]}$. 本研究中, 近岸带点位 1 和 2 水体 $\mathrm{CH}_{4}$ 浓度和饱和度远远高于其他点位, 可能是因为这两个点位均位于近岸带芦苇群丛内, 蓝藻水华长期在此堆积 (图 $1 \mathrm{~b} 、 \mathrm{c}$ )、腐烂、分解, 并向水体 中释放大量的有机质,这些有机质在微生物的作用下被矿化; 同时, 沉降在沉积物中的蓝藻残体也会在微生 物的作用下分解, 除了产生 $\mathrm{CO}_{2}$ 以外, 还会产生 $\mathrm{CH}_{4}$. 以往的研究认为湖泊沉积物是 $\mathrm{CH}_{4}$ 产生的重要场所, 但 胡万婷等 ${ }^{[25]}$ 通过对富营养化湖泊蓝藻水华分解中水体 $\mathrm{CH}_{4}$ 浓度的动态研究, 表明 $\mathrm{CH}_{4}$ 不仅来源于沉积物, 而且还可以由水体蓝藻分解过程中释放的有机质转化而来. 沉积物产生的 $\mathrm{CH}_{4}$ 并不是全部释放到大气中, 大部分在向上迁移的过程中会被以各种形式损耗, 如被 $\mathrm{O}_{2}$ 氧化、厌氧氧化等. 本研究表明, 太湖西岸近岸带 蓝藻水华堆积区是 $\mathrm{CH}_{4}$ 重要的潜在排放源, 这点与 Wang 等 ${ }^{[14]}$ 的研究一致. 此外, Juutinen 等 ${ }^{[26]}$ 对芬兰几个 湖泊 $\mathrm{CH}_{4}$ 排放的研究也表明, 湖泊近岸区域也是 $\mathrm{CH}_{4}$ 排放的重要场所. 本研究所有点位水体中 $\mathrm{CH}_{4}$ 均为过饱 和状态,表明除近岸带以外,开阔湖区也是 $\mathrm{CH}_{4}$ 的潜在排放源.

$\mathrm{N}_{2} \mathrm{O}$ 产生于微生物的硝化和反硝化过程中 ${ }^{[27]}$, 因此其在水体的浓度会受到 $\mathrm{NO}_{3}^{-}-\mathrm{N}$ 浓度的影响. 而在戻 氧及 $\mathrm{NO}_{3}^{-}-\mathrm{N}$ 浓度低的情况下, $\mathrm{N}_{2} \mathrm{O}$ 会被反硝化细菌作为电子受体所消耗 ${ }^{[28]}$. 有研究表明, 当水中 $\mathrm{NO}_{3}^{-}$浓度 小于 $0.5 \mathrm{mg} / \mathrm{L}$ 时, $\mathrm{N}_{2} \mathrm{O}$ 的消耗就会进行 ${ }^{[29]}$. 本研究中,点位 2 水体 $\mathrm{N}_{2} \mathrm{O}$ 浓度仍然最高,但是点位 1 并不均高 于其他点位. 已有研究表明, 蓝藻水华暴发会对湖泊氮循环产生重要影响, 因为大量蓝藻的存在, 其光合作 用能够通过为硝化细菌提供 $\mathrm{O}_{2}$, 而促进硝化反应, 间接为反硝化细菌提供充足的 $\mathrm{NO}_{3}^{-}-\mathrm{N}$, 因此, 在蓝藻水华 暴发时, $\mathrm{N}_{2} \mathrm{O}$ 的排放量很高 ${ }^{[15,30]}$. 此外, 研究发现, 由于竺山湾主要人湖河流为殷村港、漕桥河和太滆运河、 雅浦港、环山河, 分别在竺山湾的西部、北部和东部区域, 这些河流的存在可能是导致点位 13 15、19 和 21 25 水体中 $\mathrm{NO}_{3}^{-}-\mathrm{N}$ 浓度较高的主要原因. 研究表明, 太湖西部和北部人湖河流氮浓度明显高于对应湖区, 人 湖河流携带的氮素进入湖泊, 从而影响湖泊水体营养盐浓度 ${ }^{[31]}$. 同时, 位于殷村港、漕桥河和太滆运河附近 的点位 19、21 24 表层水体中 $\mathrm{N}_{2} \mathrm{O}$ 浓度较高, 可能是由于人湖河流输人各种形态的氮素后,在适宜条件下发 生硝化和反硝化作用, 从而产生 $\mathrm{N}_{2} \mathrm{O}$, 但是由人湖河流输人的氮素对 $\mathrm{N}_{2} \mathrm{O}$ 产生的影响和机制需要进一步研 究才能得出明确结论.

富营养化湖泊蓝藻水华暴发会对 $\mathrm{CH}_{4}$ 和 $\mathrm{N}_{2} \mathrm{O}$ 产生具有重要影响. $\mathrm{CH}_{4}$ 和 $\mathrm{N}_{2} \mathrm{O}$ 浓度与 $\mathrm{TN} 、 \mathrm{TP} 、 \mathrm{NH}_{4}^{+}-\mathrm{N}$ 、 DOC 浓度的相关性显著 $(P<0.01)$, 其中 $\mathrm{CH}_{4}$ 浓度与 DOC 浓度相关性最为显著, 表明水中的 DOC 在微生物 的代谢作用下会对 $\mathrm{CH}_{4}$ 的产生重要影响. 众多研究均表明, $\mathrm{CH}_{4}$ 的产生与可利用性有机碳浓度有关 ${ }^{[10,32]}$. Xiao 等 ${ }^{[33]}$ 对太湖 $\mathrm{CH}_{4}$ 排放的研究结果表明, 水体透明度、溶解氧浓度以及蓝藻和水生植被分布等均对 $\mathrm{CH}_{4}$ 排放有重要影响. 除 DOC 外, 水中 $\mathrm{CH}_{4}$ 和 $\mathrm{N}_{2} \mathrm{O}$ 浓度与 TP 浓度呈显著正相关, 而磷作为限制水体初级生产力 
及衡量水体富营养化的重要因子, 表明水体富营养化程度的加剧或者水体初级生产力的提高, 可能对水体 $\mathrm{CH}_{4}$ 和 $\mathrm{N}_{2} \mathrm{O}$ 的产生具有一定影响. 但是 TP 对两种温室气体产生的影响可能是间接的, 即可能是通过促进蓝 藻水华暴发而实现的,但该过程的影响机制尚不明确,需要开展深人的研究.

我国是一个多湖泊的国家, 全国共有 $1 \mathrm{~km}^{2}$ 以上的湖泊 2759 个, 其中约三分之一为淡水湖泊, 主要分布 在东部沿海和长江中下游地区, 将近 70\% 为浅水湖泊 ${ }^{[34]}$, 由于近几十年来的经济发展和对湖泊资源不合理 的开发利用, 这些湖泊大多数已经成为富营养化湖泊或者有富营养化趋势 ${ }^{[35]}$. 研究表明, 浅水湖泊对 $\mathrm{CH}_{4}$ 排 放具有重要影响. 因为产生于厌氧沉积物中的 $\mathrm{CH}_{4}$ 在向大气迁移的过程中, 能够在好氧的水柱中被氧化消 耗. 浅水湖泊相对于深水湖泊来说, $\mathrm{CH}_{4}$ 向大气迁移的时间较短, 因此其被氧化而消耗的量相对较少 ${ }^{[36]}$. 结 合本研究结果, 提出开展富营养化湖泊蓝藻水华对温室气体产生、排放的影响及机制研究对于未来我国湖 泊生态系统温室气体排放的估算具有重要意义.

太湖近岸带蓝藻堆积区是 $\mathrm{CH}_{4}$ 和 $\mathrm{N}_{2} \mathrm{O}$ 产生的热点区域, 尽管对这两种气体在水中饱和度的计算并不能 直接反映出其向大气的排放通量, 因为水中温室气体向大气的排放通量与其在水一气界面的浓度梯度、风 速、水体温度等因素有关, 但是气体在水中的饱和度能够在一定程度上反映出其向大气释放的潜力. 此外, 如果想弄清楚太湖对两种温室气体究竟扮演的是源还是汇的角色,还需要进行长时间、多点位的连续观测.

\section{4 结论}

1) 太湖近岸带蓝藻堆积区表层水体 $\mathrm{CH}_{4}$ 和 $\mathrm{N}_{2} \mathrm{O}$ 两种温室气体浓度和饱和度均高于开阔湖区, 表明太湖 近岸带蓝藻水华堆积区是温室气体产生的热点区域,具有较大的向大气迁移的潜力.

2) 人湖河流河口区域 $\mathrm{N}_{2} \mathrm{O}$ 浓度较高, 表明人湖河流的输人的氮源可能会促进水体 $\mathrm{N}_{2} \mathrm{O}$ 的产生, 但其机 制需要进一步研究.

3) 表层水体温室气体浓度与水体理化指标关系密切, 其中 $\mathrm{CH}_{4}$ 浓度与 DOC 浓度相关性最为显著, $\mathrm{N}_{2} \mathrm{O}$ 浓度与 TP 浓度相关性最为显著; 研究揭示了蓝藻水华暴发可能对湖泊温室气体的产生具有重要影响,但其 产生过程和影响机制仍然需要进一步研究.

4) 基于本研究结果, 提出开展富营养化湖泊蓝藻水华对温室气体产生、排放的影响及机制研究对于未 来我国湖泊生态系统温室气体排放的估算具有重要意义.

\section{5 参考文献}

[ 1 ] Bastviken D, Tranvik LJ, Downing JA et al. Freshwater methane emissions offset the continental carbon sink. Science, 2011, 331(6013) : 50-50. DOI: 10.1126/science.1196808.

[ 2 ] Cole JJ, Prairie YT, Caraco NF et al. Plumbing the global carbon cycle: integrating inland waters into the terrestrial carbon budget. Ecosystems, 2007, 10(1) : 172-185. DOI: 10.1007/s10021-006-9013-8.

[ 3 ] Wu QL, Xing P, Li HB et al. Impacts of regime shift between phytoplankton and macrophyte on the microbial community structure and its carbon cycling in lakes. Microbiology, China, 2013, 40(1) : 87-97. DOI: 10.13344/j.microbiol.china. 2013.01.003. [ 吴庆龙, 邢鹏, 李化炳等. 草藻型稳态转换对湖泊微生物结构及其碳循环功能的影响. 微生物学通 报, 2013, 40(1): 87-97.

[ 4 ] Carpenter SR, Caraco NF, Correll DL et al. Nonpoint pollution of surface waters with phosphorus and nitrogen. Ecological Applications, 1998, 8(3) : 559-568. DOI: 10.2307/2641247.

[ 5 ] Huttunen JT, Hammar T, Alm J et al. Greenhouse gases in non-oxygenated and artificially oxygenated eutrophied lakes during winter stratification. Journal of Environmental Quality, 2001, 30(2) : 387-394. DOI: 10.2134/jeq2001.302387x.

[ 6 ] Verpoorter C, Kutser T, Seekell DA et al. A global inventory of lakes based on high-resolution satellite imagery. Geophysical Research Letters, 2014, 41(18) : 6396-6402. DOI: 10.1002/2014GL060641.

[ 7 ] Tranvik LJ, Downing JA, Cotner JB et al. Lakes and reservoirs as regulators of carbon cycling and climate. Limnology and Oceanography, 2009, 54(6part2) : 2298-2314. DOI: 10.4319/lo.2009.54.6_part_2.2298.

[ 8 ] Battin TJ, Kaplan LA, Findlay S et al. Biophysical controls on organic carbon fluxes in fluvial networks. Nature Geoscience, 2008, 1(2) : 95-100. DOI: 10.1038/ngeo602. 
[ 9 ] Bastviken D, Cole J, Pace M et al. Methane emissions from lakes: Dependence of lake characteristics, two regional assessments, and a global estimate. Global Biogeochemical Cycles, 2004, 18(4) : GB4009. DOI: 10.1029/2004GB002238.

[10] Huttunen JT, Alm J, Saarijärvi E et al. Contribution of winter to the annual $\mathrm{CH}_{4}$ emission from a eutrophied boreal lake. Chemosphere, 2003, 50(2) : 247-250. DOI: 10.1016/S0045-6535 (02)00148-0.

[11] Gudasz C, Bastviken D, Steger K et al. Temperature-controlled organic carbon mineralization in lake sediments. Nature, 2010, 466(7305) : 478-481. DOI: 10.1038/nature09186.

[12] Walter Anthony KM, Vas DA, Brosius L et al. Estimating methane emissions from northern lakes using ice-bubble surveys. Limnology \& Oceanography Methods, 2010, 8(6) : 592-609. DOI: 10:4319/lom.2010.8.592.

[13] Marotta H, Pinho L, Gudasz C et al. Greenhouse gas production in low-latitude lake sediments responds strongly to warming. Nature Climate Change, 2014, 4(6) : 467-470. DOI: 10.1038/NCLIMATE2222.

[14] Wang H, Lu J, Wang W et al. Methane fluxes from the littoral zone of hypereutrophic Taihu Lake, China. Journal of Geophysical Research-Atmospheres, 2006, 111(D17) : 4093-4100. DOI: 10.1029/2005JD006864.

[15] Wang H, Wang W, Yin C et al. Littoral zones as the "hotspots" of nitrous oxide $\left(\mathrm{N}_{2} \mathrm{O}\right)$ emission in a hyper-eutrophic lake in China. Atmospheric Environment, 2006, 40(28) : 5522-5527. DOI: 10.1016/j.atmosenv.2006.05.032.

[16] Xing Y, Xie P, Yang H et al. Methane and carbon dioxide fluxes from a shallow hypereutrophic subtropical Lake in China. Atmospheric Environment, 2005, 39(30) : 5532-5540. DOI: 10.1016/j.atmosenv.2005.06.010.

[17] Weiss RF, BA Price. Nitrous oxide solubility in water and seawater. Marine Chemistry, 1980, 8(4) : 347-359. DOI: 10. 1016/0304-4203( 80 ) 90024-9.

[18] Wiesenburg DA, Guinasso Jr NL. Equilibrium solubilities of methane, carbon monoxide, and hydrogen in water and sea water. Journal of Chemical and Engineering Data, 1979, 24(4) : 356-360. DOI: 10.1021/je60083a006.

[19] YaoXL, Xu HX, Tang CJ et al. Denitrification potential of high suspend sediments in Poyang Lake, China. China Environmental Science, 2015, 35(3): 846-855. [姚晓龙, 徐会显, 唐陈杰等. 鄱阳湖水体悬浮物反硝化潜力模拟研究. 中 国环境科学, 2015, 35(3): 846-855.]

[20] Yan X, Xu X, Wang M et al. Climate warming and cyanobacteria blooms: Looks at their relationships from a new perspective. Water Research, 2017, 125: 449-457. DOI: 10.1016/j.watres.2017.09.008.

[21] Chen M, Li XH, He YH et al. Increasing sulfate concentrations result in higher sulfide production and phosphorous mobilization in a shallow eutrophic freshwater lake. Water Research, 2016, 96: 94-104. DOI: 10.1016/j.watres.2016.03.030.

[22] Komada T, Burdige DJ, Crispo SM et al. Dissolved organic carbon dynamics in anaerobic sediments of the Santa Monica Basin. Geochimica et Cosmochimica Acta, 2013, 110(3) : 253-273. DOI: 10.1016/j.gca.2013.02.017.

[23] Duc NT, Crill P, Bastviken D. Implications of temperature and sediment characteristics on methane formation and oxidation in lake sediments. Biogeochemistry, 2010, 100(1/2/3) : 185-196. DOI: 10.1007/s10533-010-9415-8.

[24] Lay JJ, Miyahara T, Noike T. Methane release rate and methanogenic bacterial populations in lake sediments. Water Research, 1996, 30(4) : 901-908. DOI: 10.1016/0043-1354 (95)00254-5.

[25] Hu WT, Tang Q, Sun W et al. Dissovled methane dynamics during the degradation of organic matter derived from cyanobacterial bloom. China Environmental Science, 2017, 37(2): 702-710. [胡万婷, 唐千, 孙伟等. 水体中蓝藻水华分 解产甲烷动态过程研究. 中国环境科学, 2017, 37(2) : 702-710.]

[26] Juutinen S, Alm J, Larmola T et al. Major implication of the littoral zone for methane release from boreal lakes. Global Biogeochemical Cycles, 2003, 17(4) : 1117. DOI: 10.1029/2003GB002105.

[27] Seitzinger SP. Denitrification in freshwater and coastal marine ecosystems : ecological and geochemical significance. Limnology and Oceanography, 1988, 33(4part2) : 702-724. DOI: 10.4319/lo.1988.33.4part2.0702.

[28] Usui T, Koike I, Ogura N. $\mathrm{N}_{2} \mathrm{O}$ production, nitrification and denitrification in an estuarine sediment. Estuarine Coastal \& Shelf Science, 2001, 52(6) : 769-781. DOI: 10.1006/ecss.2000.0765.

[29] Johansson AE, Kasimir Klemedtsson Å, Klemedtsson L et al. Nitrous oxide exchanges with the atmosphere of a constructed wetland treating wastewater. Tellus Series B-chemical \& Physical Meteorology, 2003, 55(3) : 737-750. DOI: 10.3402/tellusb.v55i3.16363.

[30] Jørgensen CJ, Struwe S, Elberling B. Temporal trends in $\mathrm{N}_{2} \mathrm{O}$ flux dynamics in a Danish wetland-effects of plant-mediated gas transport of $\mathrm{N}_{2} \mathrm{O}$ and $\mathrm{O}_{2}$ following changes in water level and soil mineral-N availability. Global Change Biology, 2012, 18(1) : 210-222. DOI: $10.1111 / \mathrm{j} .1365-2486.2011 .02485 . x$. 
[31] Gao YX, Cai LL, Zhao LL et al. Water quality comparison between lake Taihu and contribute river during high water-level period. Environmental Science, 2011, 32(10) : 2840-2848. DOI: 10.13227/j.hjkx.2011.10.025. [高永霞, 蔡琳琳, 赵 林林等. 丰水期环太湖河流与湖区水质比较研究. 环境科学, 2011, 32(10) : 2840-2848.]

[32] King GM, Wiebe WJ. Methane release from soils of a Georgia salt marsh. Geochimica et Cosmochimica Acta, 1978,42 (4) : 343-348. DOI: 10.1016/0016-7037 ( 78 ) 90264-8.

[33] Xiao Q, Zhang M, Hu Z et al. Spatial variations of methane emission in a large shallow eutrophic lake in subtropical climate. Journal of Geophysical Research Biogeosciences, 2017, 122(7) : 1-18. DOI: 10.1002/2017JG003805.

[34] Wang SM, Dou HS eds. Chinese lakes. Beijing: Science Press, 1998: 3-21. [王苏民, 窦鸿身. 中国湖泊志. 北京: 科 学出版社, 1998: 3-21.]

[35] Qin BQ. Approaches to mechanisms and control of eutrophication of shallow lakes in the middle and lower reaches of the Yangtze River. J Lake Sci, 2002, 14(3) : 193-202. DOI: 10.18307/2002.0301. [ 秦伯强. 长江中下游浅水湖泊富营养 化发生机制与控制途径初探. 湖泊科学, 2002, 14(3): 193-202.]

[36] Bastviken D, Cole JJ, Pace ML et al. Fates of methane from different lake habitats: Connecting whole-lake budgets and $\mathrm{CH}_{4}$ emissions. Journal of Geophysical Research Biogeosciences, 2008, 113 ( G02024): 61-74. DOI: 10. 1029/2007JG000608. 